above named have all but provoked, "imagine a locust stridulating in the centre of a mass of iron one mile in all directions" (sic). The idea is charming, countrified, bucolic, but perhaps rather cold for the poor insect! "It is admitted he could be heard, and about sixteen times quicker than in the air. ..." (the steps of this grand calculation must perforce be omitted). "The mass of iron thus displaced" (i.e. by said locust) "would weigh not less than $729,749,050,612$ tons, and would be so moved by the strength of the locust."

The thought is too tremendous! so, locust-like, I must cease to "stridulate," lest I bring down the solar system in ruins on the heads of innocent humanity.

\section{W. H. STONE}

\section{Kryptogamen-Flora von Schlesien. Vol. III.: Pilze. Bearbeitet von Dr. J. Schröter. (Breslau: J. U. Kern.)}

DR. CoHN's "Cryptogamic Flora" is already so favourably known by the portions which have appeared, that the announcement of any subsequent part is sure to be received with satisfaction. The first part of the Fungi, by Dr. J. Schröter, is just issued, and consists almost entirely of an introduction of nearly 100 pages, carefully digested and summarised, concluding with the order of classification adopted. The three groups or primary divisions are :--(1) Myxomycetes; (2) Schizomycetes; and (3) Eumycetes. The latter embraces the Chytridiei, Zygomycetes, Oomycetes, Protomycetes, Ustilaginei, Uredinei, Auriculariei, Basidiomycetes, and Ascomycetes, with an appendix for the incomplete Hyphomycetes, Tuberculariei, and Sphæropsidei. As the present part contains only a portion of the Myxomycetes, no opinion can be formed of the manner in which the foregoing skeleton will be filled up; but, as this portion is based upon Rostafinski's monograph, no exception can be taken thereto. The real difficulty lies further ahead, and whether the knot is to be untied or cut cannot be predicted.

\section{LETTERS TO THE EDITOR}

[ 7 'he Editor does not hold himself responsible for opinions expressed by his correspondents. Neilher can he undertake to ieturn, or to correspona with the writers of, rejected manuscripts. No notice is taken of anonymous communications.

[The Editor urgently requests correspondents to keep their letters as short as possible. The pressure on his space is so great that it is impossible otherwise to insure the appearance even of commurications containing interesting and novel facts.]

\section{On the Terminology of the Mathematical Theory of} Elasticity

I HAVE been greatly interested by the letters on this subject from Prof. K. Pearson (NATuRe, vol. xxxi. p. 456) and Prof. A. B. W. Kennedy (vol. xxxi. p. 504), and I have looked forward with pleasure to further communications from other eminent " elasticians." As, however, no better qualified person seems disposed to continue the correspondence, and as I am practically interested in a definite settlement of elastic terminology, I venture to offer a few remarks on the subject.

(I) Nothing could be better than Prof. Pearson's term state of ease for the condition of an elastic body when capable of enduring a certain amount of stress, without showing permanent set on its removal. This is worthy of Clifford, and is sure to make its way.

Prof. Kennedy has extended this term by applying " maximum state of ease" to the condition in which the body may be strained to its elastic limit without set. Perhaps ultimate state of ease would be more significant, and limited state of ease might be employed to denote the intermediate stages. The ultimate state of ease of course corresponds to the "natural state" of the ideal perfectly elastic solid.

At the point $B$ in Prof. Kennedy's figure we reach the limit of perfect elasticity, and enter the stage $b$ of elastic instability. Prof. Kennedy's suggestion of "limit of stability" for the point
$C$ is inconsistent with the last. I would suggest elastic crisis as an alternative for "breaking-down point." We evidently here pass the critical point in the static equilibrium of the molecules.

Perhaps $c^{\prime}$ might be called the stage of thermal inversion.

At $C_{1}$ the bar enters the plastic state-divided by Prof. Kennedy into the stage of uniform flow from $C_{1}$ to the point $D$ of maximum load and the stage of local flow from $D$ to the point $E$ of terminal load or (apparently) of maximum stress.

(2) I observe that Prof. Kennedy uses "load" and "external stress," apparently as alternative terms, and that Prof. Pearsom speaks of "stress per unit area." Would it not be advisable to settle, once for all, that stress shall always, when it stands alone, mean a force per unit area? "Stress" and "intensity of stress" would then be identical terms, while the force across a given area due to stress would be known as the "total" or "resultant stress" across the area. This is all that is required to bring the terminology of perfect elasticity into exact correspondence with that of hydromechanics, in which pressure and total or resultant pressure have always stood in this relation to one another.

(3) Next as to "tension." The word was originally adopted from the theory of strings, and of bars used like strings to sup. port weights, and was, I believe, invariably used (as it still is in the case of strings) to denote the load, or total longitudinal stress endured. Nowadays, however, it seems to be employed indifferently in this sense and in that of intensity of tensile stress. I would suggest that the term traction, which the modern French writers have freely adopted, should be invariably used to denote intensity of tensile stress, and that tension should be restored to its original signification of total or resultant traction.

"Traction" and "pressure" would then (according to the ordinary convention as to sign) be synonymous with "positive" and "negative" stress. Perhaps some ela tician would suggest a convenient abbreviation for "total pressure" or "negative tension."

(4) Is it too late to protest on behalf of that much-abused term viscosity as applied to solids? The thoroughly-established sense of the word, as applied to fluids, implies-not the property in virtue of which they undergo permanent or continued change of shape under continued distorting stress (i.e. their fluidity); but that other property in virtue of which they are able to offer more or less resistance, by means of molecular friction, to instantaneous changes of shape under stress which is not continued. In this case, therefore, viscosity is a property distinctly opposed to fluidity, and, indeed, described in terms as a falling short of "perfect fluidity."

It is thus obviously false analogy to describe a metal in the state of plastic flow as viscous, or to "appropriate this name to that permanent set which may be produced by the application for a long period of a stress well within the limits of elasticity." The latter sense-at least as applied to ice (NATURE, vol. xxxii. p. 16) - has, no doubt, a classical authority in the great memoir of Forbes ; but Sir W. Thomson has pointed out ("Enc. Brit.," Art. "Elasticity," $\$ 3 \mathbf{I}$; and Thomson and Tait's "Natural Philosophy," § 74I) that the properties of ice so described are included under the perfectly definite and convenient term plasticity, which is really analogous to fluidity.

On the other hand, analogy demands that the term viscosity, as applied to solids, shall be strictly confined to that frictional dissipation of energy which is always at work during rapid changes of strain, and which was first discovered during small vibrations within the elastic limit by Sir W. Thomson (Proc. Roy. Soc., May 18, 1865, or the passages above cited).

That the viscosity of a ductile material is very greatly increased in the plastic stage is of course beyond a doubt, the amount of energy absorbed by it on sudden increase of the stress being so much in excess of that required to provide for the increased potential energy of the accompanying strain that the temperature rises to a sensible extent. But what I wish to make clear is that the true viscosity is not essential to or characteristic of the truly plastic state, but that, on the contrary, the viscosity of a ductile solid renders it imperfectly plastic in just the same sense as a viscous fluid is imperfectly fluid.

(5) Finally, I may perhaps be permitted to add that, next to the importance to all concerned of a definite and universal terminology, comes the importance to mathematicians at least of a uniform notation.

The effect of reading through, for purposes of comparison or historical record, the Ioo odd really important treatises on this subject-in each of which a perfectly independent and generally 